\title{
GESTÃO DE DOCUMENTOS NO PROCESSO JUDICIAL ELETRÔNICO BRASILEIRO - SISTEMA MOREQ-JUS
}

\author{
DOCUMENT MANAGEMENT IN JUDICIAL PROCESS ELECTRONIC \\ BRAZIL - MOREQ-JUS SYSTEM
}

\author{
FÁBio da SiLVA Porto ${ }^{1}$
}

Recebido em: 16/12/2015

Aprovado em: 25/10/2016

\section{RESUMO}

O intuito deste estudo é demonstrar a importância da normalização na concretização da prestação jurisdicional, realizada por meio do processo judicial eletrônico. Sem os paradigmas e as regulações a serem implementadas de maneira uniforme para todas as diferentes plataformas de processo eletrônico desenvolvidas no âmbito dos órgãos do Poder Judiciário Brasileiro, não se poderia garantir a efetividade, eficácia e segurança dos autos virtuais. Assim, em virtude das peculiaridades assumidas por um sistema de solução de litígios judiciais sem precedentes no mundo, o Conselho Nacional de Justiça (CNJ) optou pela criação do Modelo de Requisitos para Sistemas Informatizados de Gestão de Processos e Documentos do Judiciário (MoReq-Jus).

Palavaras-chave: Prestação jurisdicional; Processo eletrônico; Normalização

\begin{abstract}
The purpose shed study is to demonstrate the importance of the normalization in the implementation of the adjudication held by electronic judicial proceedings. The absence of paradigms and regulations to be implemented uniformly for all the different electronic process platforms developed under the Brazilian judicial branch agencies could not guarantee the effectiveness, efficiency and security of virtual selves. The decision of the National Council of Justice - CNJ the creation of the Model Requirements for Systems Computerized Process Management and Legal Documents (MoReq-Jus), reason why of the peculiarities assumed by an unprecedented court dispute resolution system in the world.

Keywords: Adjudication; Electronic process, Normalization
\end{abstract}

1 Graduado em Direito pela Universidade Federal de Pelotas (UFPel). Mestrando no Programa de Pós-Graduação Profissional em Patrimônio Cultural (PPGPPC) da Universidade Federal de Santa Maria (UFSM). E-mail: fabio.porto.ufsm@gmail.com 


\section{Introdução}

A complexidade das relações sociais de nosso tempo e a descrença generalizada de que a própria sociedade seja capaz de resolver os conflitos resultantes dessa intrincada vida em coletividade impõem um desafio constante no campo do Direito, instrumento reconhecidamente eficaz na solução das aludidas disputas. A resolução desses conflitos interpessoais, no entanto, precisa ser absolutamente célere, sob a pena de não promover a pacificação social e não evitar o acirramento das disputas ou até mesmo sua multiplicação. Um desfecho jurídico demorado costuma desagradar a todas as partes interessadas.

No Brasil, o problema do volume de conflitos de interesses na sociedade é sustentado pelo evidente fracasso da solução consensual dos litígios, situação que normalmente estabelece um único caminho para a superação das colisões de pretensos direitos: a intervenção do Poder Judiciário. Essa fé cega de que um juiz está muito mais habilitado a resolver as lides entre indivíduos ou dos indivíduos com as instituições estabelece uma aura mítica ao magistrado brasileiro, colocando-o quase como um redentor de todos os embates existentes na sociedade. A nefasta consequência desse messianismo judicial é a explosão do número dos processos judiciais em tramitação nas mais variadas esferas do Poder Judiciário Brasileiro.

A expressiva quantidade de processos judiciais em tramitação, associada a uma taxa tímida de rápido deslinde judicial dessas demandas, leva ao acúmulo invencível de trabalho conferido aos juízes, o que acaba por provocar a demora no deslinde judicial das lides além do aceitável, razão pela qual foi inserido no texto constitucional o direito subjetivo público do jurisdicionado de receber a prestação jurisdicional em prazo razoável (Constituição Federal, 1988) $)^{1}$. Conscientes dessa indesejável 1 BRASIL. Constituição (1988). Constituição da República Federativa realidade, os diversos âmbitos de operadores do Direito - advogados, doutrinadores, juízes, membros do Ministério Público, defensores públicos, dentre outros segmentos da sociedade envolvidos com as questões jurídicas - começaram a prospectar alternativas para tornar o processo judicial mais célere e, por decorrência, mais efetivo.

Assim, além de modificações nos instrumentos legislativos que regulam o andamento do processo, seja cível, trabalhista ou penal, os atores dessa cruzada pela celeridade e efetividade processual optaram por utilizar as ferramentas tecnológicas colocadas à disposição da moderna sociedade e, mudando radicalmente de paradigmas, adotar o denominado processo eletrônico, substituindo os ecologicamente incorretos autos judiciais físicos, de papel, por autos virtuais, muito mais adequados também sob o ponto de vista ambiental. Nessa esteira, surgiu a Lei n. ${ }^{\circ} 11.419 / 2006$, que se destina a disciplinar a informatização do processo eletrônico e lançar as premissas para a gradativa substituição do processo físico pelo processo virtual. Nesse sentido, a implantação completa do intitulado processo judicial eletrônico terá de estar concluída até o final do ano de 2018, conforme a determinação expressa da Resolução n. ${ }^{\circ}$ 185/2013 do Conselho Nacional de Justiça (CNJ).

Estabelecidas as citadas metas, deparam-se os destinatários dessa nova realidade processual-virtual com enormes dificuldades a serem experimentadas nesse ambiente judicial estranho, desapegado da segurança tátil do papel. O conforto desfrutado pela representação de argumentos e elementos de defesa processual impressos no tradicional papel irá desaparecer, dando espaço a um mundo impalpável, visível apenas na realidade virtual, por meio de acesso pela rede mundial de computadores (internet).

\footnotetext{
do Brasil. Brasília, DF: Senado, 1988

Art. $5^{\circ}[\ldots]$ LXXVIII a todos, no âmbito judicial e administrativo, são assegurados a razoável duração do processo e os meios que garantam a
} celeridade de sua tramitação. 
As desconfianças decorrentes desse novo parâmetro do processo judicial são, assim, inúmeras, marcadas quase sempre pela nostálgica ideia de que, fora do universo processual físico, conferido pelo papel, não há segurança jurídica. Diante disso, pode-se questionar como se saberá que os processos eletrônicos serão seguros, que não serão destruídos ou perdidos pela ação de vírus cibernéticos ou pela atuação de hackers ou, ainda, que as peças e os documentos anexados aos autos virtuais não serão adulterados para favorecer ou prejudicar uma das partes da demanda.

A revolução processual que se encontra em curso depende, assim, decisivamente da confiabilidade que puder ser agregada ao sistema. Essa credibilidade somente será alcançada se o processo eletrônico se mostrar constantemente seguro, seja sob o enfoque da preservação dos bancos de dados do sistema, das ferramentas de segurança contra ataques externos, das credenciais exigidas dos usuários ou dos instrumentos que garantam a autenticidade dos documentos que o integrem.

A adoção de novas tecnologias que substituam o processo físico imporá ao universo jurídico um diálogo mais estreito com outras ciências. Nesse contexto, será inevitável a presença de especialistas em Tecnologia da Informação, Arquivologia e Diplomática no desenvolvimento dos sistemas processuais virtuais, que precisarão de frequente atualização, autenticação, certificação e proteção.

Essa realidade impôs ao $\mathrm{CNJ}$, responsável pela implantação e pelo desenvolvimento, em todo o território nacional, do processo eletrônico judicial, a adoção de um sistema de normalização, visando à padronização de procedimentos e à preservação da unidade do sistema, para que seus diversos subsistemas - Justiça Estadual em cada Estado-Membro e Justiça do Distrito Federal, Justiça Federal, Justiças Especializadas e Tribunais Superiores - pos- sam dialogar e tramitar processos entre si, quando necessário, sem qualquer solução de continuidade.

\section{A importância da normalização no processo judicial eletrônico no Brasil}

A substituição do tradicional processo físico, em papel, pelo ambiente virtual do processo eletrônico não poderá ser satisfatoriamente concretizada sem a adoção de rígidas regras de padronização e gestão documental, tendo em vista o imenso volume de documentos inerentes aos autos eletrônicos em tramitação. Em virtude dessa necessidade de intensa produção, anexação e circulação de documentos, não se mostra razoável que cada órgão do Poder Judiciário adote uma maneira distinta de garantir a autenticidade e integridade da documentação tramitada, porque uma diversidade de critérios e, principalmente, de normas reguladoras dessa gigantesca circulação de documentos levaria a um verdadeiro caos judicial.

Diante desse cenário, é preciso efetivar uma correta gestão de documentos, definida na legislação como "o conjunto de procedimentos e operações técnicas referentes à sua produção, tramitação, uso, avaliação e arquivamento em fase corrente e intermediária, visando a sua eliminação ou recolhimento para guarda permanente" 2 . Assim, uma das primeiras demandas para assegurar a implementação do Processo Judicial Eletrônico no Brasil foi a de respaldar a produção, a tramitação e a conservação dos documentos que seriam inseridos nesse ambiente processual virtual, objetivo que somente poderia ser atingido pela via da normalização.

É a Associação Brasileira de Normas Técnicas (ABNT), instituição que representa o Brasil no espaço internacional atinente a normas técnicas, que traz uma definição precisa do significado de normalização, conceituando-a como:

2 BRASIL. Lei n. ${ }^{\circ} 8.159 / 1991$. Publicada no Diário Oficial da União em 09 de janeiro de 1991. 
Atividade que estabelece, em relação a problemas existentes ou potenciais, prescrições destinadas à utilização comum e repetitiva com vistas à obtenção do grau ótimo de ordem em um dado contexto. Consiste, em particular, na elaboração, difusão e implementação das Normas. A normalização é, assim, o processo de formulação e aplicação de regras para a solução ou prevenção de problemas, com a cooperação de todos os interessados, e, em particular, para a promoção da economia global. No estabelecimento dessas regras recorre-se à tecnologia como o instrumento para estabelecer, de forma objetiva e neutra, as condições que possibilitem que o produto, projeto, processo, sistema, pessoa, bem ou serviço atendam às finalidades a que se destinam, sem se esquecer dos aspectos de segurança. Norma é o documento estabelecido por consenso e aprovado por um organismo reconhecido, que fornece regras, diretrizes ou características mínimas para atividades ou para seus resultados, visando à obtenção de um grau ótimo de ordenação em um dado contexto. A norma é, por princípio, de uso voluntário, mas quase sempre é usada por representar o consenso sobre o estado da arte de determinado assunto, obtido entre especialistas das partes interessadas ${ }^{3}$.

Ciente dessa situação, o Estado Brasileiro editou a Lei n. $^{\circ} 11.419 / 2016$, que dispõe sobre a informatização do processo judicial, trazendo uma primeira forma de normalização e estabelecendo alguns conceitos fundamentais gerais referentes à nova modalidade de prestação jurisdicional:

Art. $1^{\circ} \mathrm{O}$ uso de meio eletrônico na tramitação de processos judiciais, comunicação de atos e transmissão de peças processuais será admitido nos termos desta Lei.

$\S 1^{\circ}$ Aplica-se o disposto nesta Lei, indistintamente, aos processos civil, penal e trabalhista, bem como aos

\footnotetext{
3 Associação Brasileira de Normas Técnicas (ABNT). Dis-
} ponivel em: http://www.abnt.org.br/normalizacao/o-que-e/o-que-e. juizados especiais, em qualquer grau de jurisdição.

$\S 2^{\circ}$ Para o disposto nesta Lei, considera-se:

I - meio eletrônico qualquer forma de armazenamento ou tráfego de documentos e arquivos digitais;

II - transmissão eletrônica toda forma de comunicação a distância com a utilização de redes de comunicação, preferencialmente a rede mundial de computadores;

III - assinatura eletrônica as seguintes formas de identificação inequívoca do signatário:

a) assinatura digital baseada em certificado digital emitido por Autoridade Certificadora credenciada, na forma de lei específica;

b) mediante cadastro de usuário no Poder Judiciário, conforme disciplinado pelos órgãos respectivos ${ }^{4}$.

Então, seguindo uma inarredável trajetória de normalização, com o evidente intuito de formular uma gestão uniforme dos documentos integrantes do Sistema de Processo Eletrônico Nacional, o $\mathrm{CNJ}$ estabeleceu um paradigma universal a ser seguido por todos os órgãos judiciais que atuam no processo eletrônico, ou seja, optou por normalizar o referido gerenciamento por meio do Modelo de Requisitos para Sistemas Informatizados de Gestão de Processos e Documentos do Judiciário (MoReq-Jus). O MoReq-Jus é um modelo específico a ser utilizado pelo Poder Judiciário Brasileiro, que é resultado de trabalho realizado por um grupo de pesquisa que utilizou como referência o Modelo de Requisitos para Sistemas Informatizados de Gestão Arquivística de Documentos (e-ARQ), elaborado pela Câmara Técnica de Documentos Eletrônicos do Conselho Nacional de Arquivos (Conarq), e o Modelo de Requisitos para Gestão de Arquivos Eletrónicos (MoReq), desenvolvido pelo Instituto dos Arquivos Nacionais/ Torre do Tombo de Portugal. O MoReq português, por sua vez, teve como base o Model Requirements for the Management

4 BRASIL. Lei n. ${ }^{\circ} 11.419 / 2006$. Publicada no Diário Oficial da União em 20 de dezembro de 2006. 
of Electronic Records (MoReq), elaborado pelo programa Intercâmbio de Dados entre Administrações (IDA) da Comissão Europeia.

Observe-se que as peculiaridades do processo eletrônico e suas diversas plataformas em funcionamento em diversos órgãos do Poder Judiciário, que não estavam interoperáveis, não permitiam o emprego direto de um dos modelos supracitados, razão pela qual se tornou inevitável a criação de novo modelo específico. Importante salientar, ainda, que o $\mathrm{CNJ}$, ao estabelecer a normalização para produção, tramitação e custódia de documentos, optou, confessadamente, por inserir o Poder Judiciário Brasileiro no contexto mundial referente à matéria de Preservação Documental, como atesta a justificativa acerca da adoção do MoReq-Jus:

O Modelo de Requisitos para Sistemas Informatizados de Gestão de Processos e Documentos do Poder Judiciário (Moreq-Jus) apresenta os requisitos que os documentos digitais produzidos pelo Judiciário e os sistemas informatizados de gestão documental deverão cumprir, no intuito de garantir a segurança e a preservação das informações, assim como a comunicação com outros sistemas. A ideia é criar um padrão uniforme de elaboração de sistemas processuais e de gestão documental capaz de atender às necessidades e de se adaptar às particularidades dos diferentes órgãos da Justiça brasileira. Ao adotar o MoReq-Jus, o CNJ está dando efetividade às recomendações da Carta da Organização das Nações Unidas para a Educação, a Ciência e a Cultura (Unesco) para a Preservação do Patrimônio Arquivístico Digital, que incentiva o estabelecimento de políticas públicas, metodologias e normas que minimizem a fragilidade de softwares e assegurem, ao longo do tempo, a autenticidade, a integridade e o acesso contínuo de documentos por todos os segmentos da sociedade ${ }^{5}$.

5 Conselho Nacional de Justiça (CNJ). Disponível em: http://www.cnj. jus.br/programas-e-acoes/pj-proname/sistema-moreq-jus.
Nesse sentido, segundo a Resolução n. ${ }^{\circ}$ 91, de 29 de setembro de 2009, que instituiu o MoReq-Jus, o objetivo dessa padronização é garantir a observância de requisitos mínimos para os diversos sistemas adotados no âmbito do processo eletrônico, assegurando confiabilidade, autenticidade e acessibilidade dos documentos geridos nas diferentes plataformas de processo eletrônico existentes. Tal normalização pretende, ainda, uniformizar padrões mínimos de confecção, tramitação, guarda, destinação, armazenamento, preservação, recuperação, arquivamento e recebimento de processos e documentos digitais, não digitais ou híbridos gerenciados pelos sistemas informatizados do Poder Judiciário.

Levando em consideração a imprescindibilidade de virtualização de toda a atividade desenvolvida no espectro do Poder Judiciário, o MoReq-Jus estabelece processos e requisitos mínimos para um Sistema Informatizado de Gestão de Processos e Documentos, denominado GestãoDoc. Diante disso, verifica-se que o CNJ entendeu a importância da correta gestão documental e de seu protagonismo na efetivação da transformação do processo judicial brasileiro, impondo adesão integral e compulsória dos sistemas de processo eletrônico ao MoReq-Jus e submetendo -os à avaliação de conformidade, disciplinada e procedida pelo próprio $\mathrm{CNJ}$.

Note-se que as regras de normalização instituídas para aplicação universal na órbita do Poder Judiciário Brasileiro, que regula a gestão documental desde os juízes singulares até o Supremo Tribunal Federal (STF), devem ser atendidas tanto para os processos administrativos (atividade-meio) quanto para os processos judiciais (atividade-fim). A citada normalização abrange tanto as tramitações de documentos internas do Poder Judiciário, indispensáveis para seu funcionamento orgânico, quanto os processos judiciais, representativos da atividade típica do Poder Judiciário, que consiste em aplicar o Direito aos 
casos concretos, solvendo os conflitos trazidos ao Juízo.

A gestão documental vai atentar, assim, para documentos produzidos por fontes internas e, especialmente, por fontes externas no que concerne ao processo judicial eletrônico. Exemplo muito palpável da incidência da normalização no processo eletrônico é a opção de padronização de documentos a serem criados para tramitação nas plataformas do Processo Judicial Eletrônico (PJe), que deverá ser o modelo único de plataforma para todos os órgãos do Poder Judiciário e que consiste em empregar como documento padrão o $\mathrm{PDF} / \mathrm{A}$, por sua confiabilidade, como se verifica nas Orientações sobre Peticionamento Eletrônico no Sistema PJe da Justiça do Trabalho, que assim refere:

O ATO CSJT.GP.SG No 423/2013 faculta, em seu Art $1^{\circ}$, o peticionamento em PDF em processos eletrônicos no sistema PJe-JT, conforme a seguir transcrito:

Art. $1^{\circ}$ Facultar o peticionamento inicial e incidental no sistema Processo Judicial Eletrônico da Justiça do Trabalho mediante a utilização do editor de texto do sistema ou da juntada de arquivo eletrônico, tipo Portable Document Format (.pdf), de qualidade padrão "PDF/A.

O QUE É PDF/A?

O PDF/A, também conhecido como ISO 19005-1, foi o primeiro padrão ISO que aborda a crescente necessidade de manter as informações armazenadas em documentos eletrônicos por longos períodos de tempo. O PDF/A é um derivado da especificação da indústria, o PDF, com restrições e algumas pequenas adições que tornam um PDF confiável e adequado para armazenamento e leitura por longos períodos de tempo ${ }^{6}$.

Importa, ainda, destacar que, ao

6 Orientaç̃es sobre peticionamento em PDF-A no sistema Pje-JT. Disponível em: http://www.trt4.jus.br/content-portlet/download/364/TRT4-Orientacoes_sobre PDF-A.pdf. Acesso em 01/12/2015. contrário da normalização dirigida ao setor privado da sociedade, cuja observância é voluntária, com raras exceções, como as contidas no Código de Defesa do Consumidor (CDC), que, pela relevância da defesa das relações de consumo, impõe a obrigatoriedade de respeito às regras de normalização, a normalização assumida pelo Poder Público vai um pouco mais além, criando uma espécie de normalização-normativa, porque está prevista, geralmente, em instrumentos legislativos, de caráter cogente (cuja aplicação não pode ser afastada pelos destinatários).

No que concerne à segurança da informação, que "pode ser definida como a proteção contra um grande número de ameaças às informações, de forma a assegurar a continuidade do negócio, minimizando danos comerciais e maximizando o retorno de possibilidades e investimentos", o MoReq-Jus incorporou a normalização contida na ISO 17799 e a ISSO 27001, com o intuito de dotar o processo eletrônico de elevada confiabilidade. Nesse sentido, houve a imposição de controle de acesso aos documentos, sendo possível o rastreamento dos acessos e, consequentemente, da trilha de auditoria.

Além disso, por força das disposições do MoReq-Jus, as plataformas de processo eletrônico têm de ser capacitadas para efetuar cópias de segurança, propiciando a guarda e a conservação dos documentos e dos seus metadados e garantindo sua rápida recuperação. $\mathrm{Na}$ esfera do Processo Judicial Eletrônico, a obrigatoriedade de respeito à normalização relativa à produção, à tramitação, à conservação e a outras ações direcionadas aos documentos constantes dos autos judiciais virtuais é uma medida que fortalece a segurança jurídica, auxiliando a concretização do Princípio do Devido Processo Legal, insculpido no art. $5^{\circ}$, inciso LIV, da Constituição Federal de 1988.

Por fim, é preciso referir que o 7 Disponível em: http://www.informabr.com.br/nbr.htm. Acesso em 01/12/2015. 
Novo Código de Processo Civil, Lei n. ${ }^{\circ}$ $13.105 / 2015$, que entrou em vigência em abril de 2016, dedicou uma Seção especialmente para tratar dos documentos eletrônicos, disciplinando, em seu art. 441, que "serão admitidos documentos eletrônicos produzidos e conservados com a observância da legislação específica"8. Notadamente, a legislação específica mencionada é aquela pertinente à normalização-normativa dos processos e documentos, cuja ausência de cumprimento levará à inadmissão do documento.

Todos esses aspectos demonstram a relevância que a normalização vem experimentando no campo jurídico, passando a ser verdadeiro suporte de credibilidade e segurança para o Processo Eletrônico Brasileiro, instrumento de efetivação da prestação jurisdicional e, por consequência, de pacificação social.

\section{Considerações finais}

Indubitavelmente, o processo judicial eletrônico não consiste mais em uma mera inovação tecnológica, refletindo, na realidade, uma política pública, que precisa ser normalizada, para que se atinja a devida eficácia em sua utilização e a indispensável eficiência, princípio constitucional da atuação do Poder Público, alcançando a maior amplitude possível com o menor dispêndio de recursos públicos. O jurisdicionado, que passa a ter acesso direto aos autos pela internet, seu representante judicial e todos os demais atores envolvidos nos processos judiciais eletrônicos brasileiros não possuem a exata dimensão da amplitude de processos de gestão documental para que se entregue a efetiva prestação jurisdicional no Brasil, na forma virtual.

Para que o Poder Judiciário concretize inúmeros direitos, por intermédio do processo judicial eletrônico, diariamente são observadas e aprimoradas normas procedimentais de funcionamento das plataformas tecnológicas que 8 BRASIL, Código de Processo Civil - Lei no ${ }^{\circ}$ 13.105/2015. Publicada no Diário Oficial da União em 17 de março de 2015. abrigam esses processos judicias, garantindo a correta, segura e padronizada tramitação e gestão de documentos que integram os autos virtuais. Sem essa normalização-normativa, o Processo Judicial Eletrônico no Brasil não seria uma promissora realidade.

\section{Referências}

ABNT - Associação Brasileira de Normas Técnicas. Disponível em http:// www.abnt.org.br/normalizacao/o-que -e/o-que-e . Acesso em 01/12/2015.

BRASIL, Código de Processo Civil Lei n. 13.105/2015. Publicada no Diário Oficial da União em 17 de março de 2015.

BRASIL. Constituição (1988). Constituição da República Federativa do Brasil. Brasília, DF: Senado, 1988.

BRASIL. Lei n. 11.419/2006. Publicada no Diário Oficial da União em 20 de dezembro de 2006.

CNJ - CONSELHO NACIONAL DE JUSTIÇA. Disponível em http://www. cnj.jus.br/programas-e-acoes/pj-proname/sistema-moreq-jus. Acesso em $01 / 12 / 2015$.

TRT4 - Tribunal Regional do Trabalho da $4^{\text {a }}$ Região. Disponível em http:// www.cnj.jus.br/programas-e-acoes/ pj-proname/sistema-moreq-jus. Acesso em 01/12/2015. 